\title{
Some Reflections on Early History
}

\author{
J. C. R. Licklider \\ Massachusetts Institute of Technology
}

\begin{abstract}
The ideas and developments reviewed briefly are mainly from six sources: (1) the M.I.T. Lincoln Laboratory during the middle and late 1950s, (2) Bolt Beranek and Newman in 1957-1962, (3) the ARPA program in 1962-1964. (4) IBM Research in 1964-1966. (5) Ivan Sutherland's lab at Harvard in 1967, and (6) Project MAC at M.I.T. in 1968-1972.

For instance, there were (1) cloud filter stations with light guns and light pens, (2) a single $1024 \times 1024$ scope display time-shared four ways and a workstation for studying technical documents, (3) Rand tablets. Teagher tables, and Bernstein's horizontal text-editing display onto which both the human editor and the computer editor could write (and understand each other). (4) a computer system especially for computer-based education and a powerful vector graphics display system. (5) a PDP-1-based, single-user workstation with four display screens, a paper tape unit. a magnetic tape unit, a printer, and the beginnings of Sutherland's virtual space displays, and (6) graphics over the ARPANET and a multi-window workstation based on the Evans and Sutherland LDS-1.

One of the key insights to be offered explains why workstations have vertical instead of horizontal (desk-like) display surfaces. Part of the plot is that. when. in the $50 \mathrm{~s}$ or $60 \mathrm{~s}$, a cathode-ray tube was mounted face-up. some of the phosphor fell down onto the electron gun and caused a short circuit. Another part is that Fredkin and DEC simply got mixed up about which way the PDP-1 display ought to swivvel.
\end{abstract}

